\title{
Examining the Performance of Indian Exchange Traded Funds (ETFs)
}

\author{
Naman SETHI
}

\begin{abstract}
Exchange traded funds (ETFs) are known to be a highly attractive mean of investment in today's financial markets. The present study is an attempt to explain the risk and return features of Indian ETFs and their trading and expense characteristics. The performance of ETFs is measured and compared with their underlying indices. It is found that they underperformed the indices, the reasons being they load their investors with extra risk than their underlying indices. Further, it is found that tracking error is having a positive relationship with expenses and risk of ETFs. Interestingly, the average number of trades and the lagged return of previous day do not affect the volume of shares. The study uses daily closing prices, intraday high and low prices and the volume of the traded shares of 10 ETFs listed on the National Stock Exchang for the period $1^{\text {st }}$ July, 2010 to $30^{\text {th }}$ June, 2015. The non-included ETFs suffer from the restrictions of non-availability of historical prices for at least five years.
\end{abstract}

Keywords: Exchange Traded Funds, Tracking Error, Risk, Return, Expense ratio

JEL Code Classification: G11

UDC: 336.762(540)

DOI: https://doi.org/10.17015/ejbe.2016.018.04

\footnotetext{
*Assistant Professor, Department of Commerce, Chaudhary Devi Lal University, Sirsa, India. E-mail: namansethi86@yahoo.com 


\section{Introduction}

Passive portfolio management works on a long term basis and it's a buy-and-hold strategy. The entire process involves tracking a particular index and this approach is called as indexing. Occasional balancing may be required as the dividend need to be reinvested because stocks merge or drop out of the target index and other stocks are added. Basically the intention of indexed portfolio is to equalize the performance and not to "beat" the target index. The performance of the manager is evaluated on the basis of his proficiency of tracking the target index. This relates to the fact that there is a minimal deviation between portfolio and index earnings. Financial specialists can build their own passive investment portfolios that follow the particular equity index and for the same there are more than two "prepackaged" approaches for achieving this goal and it's more beneficial and less costly for the petite investor. These are (1) buying shares in an index mutual fund or (2) buying shares in an exchange-traded fund (ETF). There is ample literature available on mutual funds; hence, the present study focuses on ETFs for analyzing a number of testable hypotheses associated to the knack of ETF managers for replicating the behavior and performance of the underlying index, the factors which may affect the ETFs trade behavior and the extent of the tracking error.

In the current era of financial markets, the exchange traded funds (ETFs) are measured as a highly important mean of the investment. ETFs are an enormously successful form of the basket securities, which allow the investors for trading a set of securities or stocks effortlessly and rapidly via one transaction. Additionally, the exchange traded finances allow the investors for obtaining the uses which are aroused out of the portfolio diversification. It can also help in following the performance of the principal indexes, exclusive of bearing the high transaction costs (Lin et al, 2006). The Exchange Traded funds (ETFs) are open-ended index based funds which are planned and may be traded on the exchanges such as stock equity based on the price of metal. Ferri (2007) clears the ETFs as "ETFs are known as the baskets of securities which can be traded, for example, individual stocks, by a brokerage firm on the stock exchange." The majority of the ETFs alleges the lower annual expenses than the index mutual funds. Though in regard to the stocks, one should pay the brokerage for buying and selling the ETF units, which can be a considerable shortcoming for the individuals who operate recurrently or may invest standard volume of money.

Index tracking has been extensively commended in the preparation and in principal as an endearing strategy for long term investment. This is like a real-time experience which is faced globally by the majority of managed funds which are under-performing in comparison to their particular benchmarks since the past course. For the past 20 years in the US, the fund managers have under-performed for the indices listed on S\&P 500 with an average of $65 \%-80 \%$. William Sharpe, a Nobel laureate in Economics, considers that all the active fund managers collectively can certainly not outperform the market. Subsequently, all the classes 
of investors viz. Institutions and the retail are progressively rising towards investing in only the well-defined indices, which are competently managed. In reality, the largest mutual fund scheme today is index funds based on the S\&P 500 managed by Vanguard. This study focusses on the ETFs traded on the NSE for analyzing a number of the testable hypotheses associated to: the knack of ETF managers for replicating the behavior and the performance of the underlying index, the factors which may affect the ETFs trade behavior, the role which may cost on the ETF performance, the extent of the tracking error. The practical evidence for a few of these hypotheses subsist on the ETFs which are being traded in the U.S., Canada, Australia, and Asian markets except an academic research on the Indian ETFs seems to be absent. Through analyzing the trading behavior of the Indian ETFs the study not only facilitates the market participants with the information on the mechanism of the market, but it also allows for the comparisons with ETFs in other emerging markets. The investor's are required to take positions in the whole market instead of focussing on a particular portfolio is the outcome of the pragmatic research/analysis proof based on the mutual funds which may facilitate the active management, on the average which doesn't fabricate the above-normal returns. Gruber (1996) stated that the quality of the professional inability to "strike the market" to the augmented expenses which are basically incurred by the managers in an effort to complete so. In resultant, the returns which are aboveaverage and being achieved on the gross levels tend to get reduced to the normal level once the expenses are being subtracted. This consciousness has lead to the investors express most of their money to the mutual funds which may track the market index instead of a mutual fund which possibly assures to "beat the market." Such kind of investors' inclination led to the growth of index funds based on the index providers of the world's biggest asset managers. Moreover, by tracking the market, investors desire to take the positions in and out of the whole market rapidly with only one order, incurring lowest transaction costs, lesser tax burden and subsequently associated with greater risk of diversification and elasticity. The endeavor to integrate these features in the product led to the development of ETFs with the successful explosion all through the developed capital markets.

\section{Review of Previous Studies}

The benefits and advantages ETFs offer to investors have been analyzed in an array of developed markets. Dellva (2001) examined one mutual fund and two ETFs that followed the S\&P 500 index and performed a simulation exercise. He found that the small and short term investors were benefitted the most by investing in this mutual fund. The study was somewhat insubstantial, as only one index and three investment vehicles were studied. Empirical conclusions based upon the study might prove to be weak. This study was of a little help to investors who want to follow a broad market index. Frino and Gallagher (2002) examined the performance of index equity funds in Australia and documented the existence of significant tracking error. They found considerable variation in performance both 
across funds and through time. Fund cash flows, the cost of trading stocks in the index portfolio, the volatility of the benchmark and the investment strategy used by the fund manager had a significant impact on the magnitude of tracking error. A little evidence of bias was found in fund performance over the sample period. Frino, Gallagher and Oetomo (2005) conducted the empirical examination of daily trading and portfolio configuration strategies of index and enhanced index equity funds. They found that these funds earned returns and exhibited risk corresponding to their underlying indices. Enhanced index funds were found to incur lower trading costs. During index revision periods, index and enhanced index funds experienced significantly higher trade difficulty. Gastineau (2004) examined the historical returns of iShares, Spiders, and Vanguard indexes following the S\&P 500 and the Russell 2000 and found that the ETFs typically underperform their respective index funds. Transaction costs were found to be the main reason for this under performance. Although there were no legal barriers against this timing in ETFs, ETF managers had not adopted this method of cost reduction. Milonas and Rompotis (2006) examined the ETFs traded on the Swiss stock exchange and found that ETFs underperform their underlying indexes while having more standard deviations than the latter, which suggested that they did not adopt full replication strategies. Tracking error was found to be $1.02 \%$ which was statistically significant and was positively related to management fees and risk of ETFs. Expenses were found to be having a negative effect on returns to investors by 0.35 units. Welch (2007) used daily data on ETFs and found that no index return had followed the normal distribution. For this reason, the nonparametric Wilcoxon Signed-Ranks Test was used and it was found that a large number of index funds did not reproduce the same median returns as their indexes. But when the ETFs following the same index were compared, no significant differences were found. Wang Hussain and Ahmed (2010) studied the developments of the gold exchange traded funds and future scenario, specifically in China. Their study shows that the gold exchange traded fund is an affluent product to invest in the gold and holds a very constructive implication for the foreign exchange, financial safety and avoiding the inflation in the country. The Gold ETF projects broad prospects in China while the government is required to support and assist the gold buying by the Chinese public. In the last quarter of year, 2009, first time in history, while outshining India, China became the world's largest gold purchaser. This might have directed to augment in Chinese gold reserves and increasing more opportunities for investors as well. The launch of the Gold ETFs has enhanced the China's capacity to transact with the issues of the diversification, the inflation protection and currency hedging. Pastor (2012) analyzed the fund features that may conclude the performance relative to the index and the fund flow of the S\&P 500 index. They indepth analyzed the indices trend during the decade from 2003 to 2012 . They have found no evidence in regard to the fund proliferation post 2008, whereas the proliferation type and the fee dispersions got confirmed. They argued the key industry trends captivating the subsample of mutual fund industry and assessed the key determinants of the fund 
performance and the relative fund flows. They checked the results again on the grounds of robustness and then carried out the comparison for varied types of funds and assessing the relative economic conditions. They suggested that by choosing the bigger fund having the small fees and holds an enhanced performance. Dhanda, Batra and Anjum (2012) also assessed the performance of open ended schemes in regard of mutual funds in for risk and return assessment. Taking BSE 30 as a benchmark during the period of $1^{\text {st }}$ April, 2009 to $31^{\text {st }}$ March, v2011, the performance was considered and appraised using the Beta, Standard Deviation, Sharpe ratio and Treynor ratio. The research derived the results that, all the schemes have performed better than their set benchmark except ING core equity fund and the Kotak select focus fund. Prajapati and Patel (2012) critically analyzed the performance of Indian mutual funds by the relative performance index, its associated risk-return analysis, Treynor's and Sharp's ratio, Sharp's, Fama's and the Jensen's measure. So, for Closing NAVs, the period referred was from $1^{\text {st }}$ January, 2007 to $31^{\text {st }}$ December, 2011. Mostly the mutual funds has able to get and attain the positive returns during 2007-2011. In fact, Beta was found to be less than the unity of all the sample mutual funds, which implies that they were less unpredictable or volatile than the index. In contrary, the results of the beta shows close to one indicates that the fund may closely match the performance of their indices. Len, Mercado, and Rejendra (2014) showed that assets for ETFs listed in Europe increased significantly due to the expectations of strong equity market in 2014 and it also lead to increased retail participation. Developed market equities recorded a significant win during 2013. Within commodities most of the sectors experienced significant pullbacks with the exception of Crude Oil, which posted modest gains. Similarly, the fixed income segment experienced weakness with the exception of High Yield and Low Duration exposures. Equities might be benefitted due to weakness in commodities as these are dependent upon low priced commodities. S\&P 500 was up by $32 \%$ in US, $59 \%$ in Nikkei (JPY), $22 \%$ in the Stoxx 600 (EUR), and $23 \%$ in MSCI EAFE (USD).

Taking cue from previous research, the study estimates the risk-return and performance of 10 Indian ETFs traded on NSE during the period 2010-2015. The study provides three measures of tracking error and examines the tracking ability of ETF managers. An attempt is also made to assess whether risk and management expenses influence the magnitude of tracking error. Another issue examined in this study is the assessment of ETFs trading activity and the factors which are likely to explain the growing activity of trading volume.

\section{ETFs in India}

Table 1 presents the details of 10 ETFs trading in National Stock Exchange of India regarding their symbol, launch date and the underlying index.

For the sake of uniformity and to make the analysis comparable, the closing prices, Total Traded Quantity and Turnover for all these ETFs for the period $1^{\text {st }}$ July, 2010 
Naman SETHI

to $30^{\text {th }}$ June, 2015 have been taken. Detailed statistics regarding each ETF's turnover, percentage share, and turnover growth during the period 2010-2015 are presented in Table 2 Panel A of Table 2 reveals that the total turnover of NIFTYBEES is highest among all the ETFs i.e. Rs. 2583.85 lakhs and that of QNIFTY is lowest with Rs. 3.44 lakhs. BANKBEES experienced highest growth from the year 2010 to 2015, its turnover raised from Rs. 22.78 lakhs to Rs. 957.94 lakhs, while for KOTAKNIFTY it raised from Rs. 7.32 lakhs to Rs. 183.76 lakhs. On the contrary, turnover of M50 dropped from Rs. 212.78 to Rs. 7.08. Likewise, if the average turnover of all the years is considered, it raised from Rs. 88.9 lakhs to Rs. 468.75 lakhs.

\section{Table 1. Details of Sample ETFs}

\begin{tabular}{lll}
\hline Symbol & Launch date & Underlying Asset \\
\hline NIFTYBEES & Jan-02 & Nifty \\
JUNIORBEES & Feb-03 & Junior Nifty \\
BANKBEES & May-04 & Bank Nifty \\
QNIFTY & May-08 & Nifty \\
RELBANK & Aug-08 & Bank Nifty \\
SHARIABEES & Jan-09 & Shariah Index \\
KOTAKNIFTY & Jan-10 & Nifty \\
M50 & Jun-10 & Nifty \\
RELGRNIFTY & Jun-10 & Nifty \\
INFRABEES & Sep-10 & CNX Infra Index \\
\hline
\end{tabular}

Source: Official website of National Stock Exchange of India

Table 2. Market Statistics of ETFs

Panel A

Yearly Turnover (in Lakhs)

\begin{tabular}{|c|c|c|c|c|c|c|c|c|}
\hline ETF & $\begin{array}{c}1^{\text {st }} \text { July to } \\
31^{\text {st }} \text { Dec. } \\
2010\end{array}$ & $\begin{array}{c}1^{\text {st }} \text { Jan to } \\
31^{\text {st }} \text { Dec. } \\
2011\end{array}$ & $\begin{array}{c}1^{\text {st } J a n} \\
\text { to } 31^{\text {st }} \\
\text { Dec. } \\
2012 \\
\end{array}$ & $\begin{array}{l}1^{\text {st } J a n ~} \\
\text { to } 31^{\text {st }} \\
\text { Dec. } \\
2013\end{array}$ & $\begin{array}{l}1^{\text {st }} \text { Jan } \\
\text { to } 31^{\text {st }} \\
\text { Dec. } \\
2014\end{array}$ & $\begin{array}{c}1^{\text {st }} \text { Jan } \\
\text { to } \\
30^{\text {th }} \text { June } \\
2015\end{array}$ & $\begin{array}{c}\text { All } \\
\text { Period }\end{array}$ & Average \\
\hline NIFTYBEES $^{1}$ & 447.00 & 619.06 & 393.94 & 295.16 & 341.94 & 486.75 & 2583.85 & 430.64 \\
\hline JUNIORBEES ${ }^{2}$ & 102.20 & 47.48 & 25.13 & 32.51 & 43.55 & 30.13 & 281.00 & 46.83 \\
\hline BANKBEES $^{3}$ & 22.78 & 37.04 & 23.71 & 28.38 & 46.09 & 957.94 & 1115.96 & 185.99 \\
\hline QNIFTY $^{4}$ & 0.42 & 0.44 & 0.67 & 0.46 & 0.94 & 0.51 & 3.44 & 0.57 \\
\hline RELBANK $^{5}$ & 3.08 & 1.16 & 2.00 & 1.70 & 2.93 & 7.64 & 18.50 & 3.08 \\
\hline SHARIABEES $^{6}$ & 0.44 & 0.26 & 0.29 & 0.34 & 0.41 & 1.95 & 3.68 & 0.61 \\
\hline KOTAKNIFTY & 7.32 & 29.29 & 56.86 & 15.99 & 77.34 & 183.76 & 370.57 & 61.76 \\
\hline$\overline{M 50^{8}}$ & 212.78 & 26.28 & 11.79 & 13.87 & 10.63 & 7.08 & 282.43 & 47.07 \\
\hline RELGRNIFTY $^{9}$ & NA & 3.82 & 2.33 & 0.55 & 0.53 & 0.31 & 7.55 & 1.51 \\
\hline INFRABEES $^{10}$ & 4.11 & 1.22 & 2.37 & 1.00 & 7.00 & 4.79 & 20.49 & 3.42 \\
\hline Total & 800.13 & 766.05 & 519.09 & 389.95 & 531.37 & 1680.87 & 4687.46 & 781.24 \\
\hline Average & 88.90 & 76.61 & 51.91 & 38.99 & 53.14 & 168.09 & 468.75 & 78.12 \\
\hline
\end{tabular}




\section{Table 2 (cont.) Market Statistics of ETFs}

\begin{tabular}{|c|c|c|c|c|c|c|c|c|}
\hline \multirow[t]{2}{*}{ Panel B } & \multicolumn{8}{|c|}{ Percentage share (\%) } \\
\hline & $\begin{array}{l}1^{\text {st }} \text { July } \\
\text { to } 31^{\text {st }}\end{array}$ & $\begin{array}{l}1^{\text {st }} \text { Jan to } \\
31^{\text {st }} \text { Dec. }\end{array}$ & $\begin{array}{l}1^{\text {st }} \text { Jan to } \\
31^{\text {st }} \text { Dec. }\end{array}$ & $\begin{array}{l}1^{\text {st }} \text { Jan to } \\
31^{\text {st }} \text { Dec. } \\
2013\end{array}$ & $\begin{array}{l}1^{\text {st }} \text { Jan to } 1^{\text {st }} \\
31^{\text {st }} \text { Dec. } 30 \\
2014\end{array}$ & $\begin{array}{l}\text { st Jan to } \\
30^{\text {th }} \text { June } \\
2015\end{array}$ & $\begin{array}{c}\text { All } \\
\text { Period }\end{array}$ & Average \\
\hline NIFTYBEES & 55.87 & 80.81 & 75.89 & 75.69 & 64.35 & 28.96 & 55.12 & 55.12 \\
\hline JUNIORBEES & 12.77 & 6.20 & 4.84 & 8.34 & 8.20 & 1.79 & 5.99 & 5.99 \\
\hline BANKBEES & 2.85 & 4.84 & 4.57 & 7.28 & 8.67 & 56.99 & 23.81 & 23.81 \\
\hline QNIFTY & 0.05 & 0.06 & 0.13 & 0.12 & 0.18 & 0.03 & 0.07 & 0.07 \\
\hline RELBANK & 0.38 & 0.15 & 0.38 & 0.44 & 0.55 & 0.45 & 0.39 & 0.39 \\
\hline SHARIABEES & 0.05 & 0.03 & 0.06 & 0.09 & 0.08 & 0.12 & 0.08 & 0.08 \\
\hline KOTAKNIFTY & 0.91 & 3.82 & 10.95 & 4.10 & 14.56 & 10.93 & 7.91 & 7.91 \\
\hline M50 & 26.59 & 3.43 & 2.27 & 3.56 & 2.00 & 0.42 & 6.03 & 6.03 \\
\hline RELGRNIFTY & NA & 0.50 & 0.45 & 0.14 & 0.10 & 0.02 & 0.16 & 0.19 \\
\hline INFRABEES & 0.51 & 0.16 & 0.46 & 0.26 & 1.32 & 0.29 & 0.44 & 0.44 \\
\hline Total & 100.00 & 100.00 & 100.00 & 100.00 & 100.00 & 100.00 & 100.00 & 100.0 \\
\hline \multirow[t]{2}{*}{ Panel C } & \multicolumn{8}{|c|}{ Yearly Turnover Growth (\%) } \\
\hline & $\begin{array}{l}1^{\text {st }} \text { July to } \\
31^{\text {st }} \\
\text { Dec, } 2010\end{array}$ & $\begin{array}{l}1^{\text {st }} \text { Jan to } \\
31^{\text {st }} \text { Dec. } \\
2011\end{array}$ & $\begin{array}{c}1^{\text {st }} \text { Jan tc } \\
31^{\text {st }} \text { Dec } \\
2012\end{array}$ & $\begin{array}{cc}\text { o } & 1^{\text {st }} \text { Jan t } \\
& 31^{\text {st }} \mathrm{Dec} \\
2013\end{array}$ & $\begin{array}{cc}\text { to } & 1^{\text {st }} \text { Jan to } \\
\text { c. } & 31^{\text {st }} \text { Dec. } \\
2014\end{array}$ & $\begin{array}{cc}\text { o } & 1^{\text {st }} \mathrm{Jan} \\
\text { c. } & 30^{\text {th }} \mathrm{Ju} \\
& 2015\end{array}$ & & riod \\
\hline NIFTYBEES & NA & 38.49 & -36.36 & -25.08 & 15.85 & 42.3 & & 8.89 \\
\hline JUNIORBEES & NA & -53.55 & -47.06 & 29.34 & 33.95 & -30.8 & & -70.52 \\
\hline BANKBEES & NA & 62.57 & -35.98 & 19.69 & 62.40 & 1978. & & 4104.40 \\
\hline QNIFTY & NA & 4.23 & 51.55 & -30.81 & 103.12 & -45.8 & & 20.27 \\
\hline RELBANK & NA & -62.45 & 72.65 & -15.00 & 72.93 & 160.2 & & 147.94 \\
\hline SHARIABEES & NA & -39.82 & 10.76 & 16.29 & 20.05 & 380.3 & & 346.98 \\
\hline KOTAKNIFTY & NA & 300.40 & 94.12 & -71.89 & 383.81 & 137.6 & & 2411.74 \\
\hline M50 & NA & -87.65 & -55.14 & 17.68 & -23.37 & -33.3 & & -96.67 \\
\hline RELGRNIFTY & NA & NA & -39.12 & -76.39 & -3.03 & -41.4 & & -91.84 \\
\hline INFRABEES & NA & -70.20 & 93.57 & -57.88 & 602.06 & -31.5 & & 16.77 \\
\hline Total & NA & -4.26 & -32.24 & -24.88 & 36.27 & 216.3 & & 110.07 \\
\hline Average & NA & -13.83 & -32.24 & -24.88 & 36.27 & 216.3 & & 89.07 \\
\hline \multicolumn{9}{|c|}{${ }^{1}$ Data available from $01 / 07 / 2010$ to $30 / 06 / 2015$} \\
\hline \multicolumn{9}{|c|}{${ }^{2}$ Data available from $01 / 07 / 2010$ to $30 / 06 / 2015$} \\
\hline \multicolumn{9}{|c|}{${ }^{3}$ Data available from $01 / 07 / 2010$ to $30 / 06 / 2015$} \\
\hline \multicolumn{9}{|c|}{${ }^{4}$ Data available from $01 / 07 / 2010$ to $30 / 06 / 2015$} \\
\hline \multicolumn{9}{|c|}{${ }^{5}$ Data available from $01 / 07 / 2010$ to $30 / 06 / 2015$} \\
\hline \multicolumn{9}{|c|}{${ }^{6}$ Data available from $01 / 07 / 2010$ to $30 / 06 / 2015$} \\
\hline \multicolumn{9}{|c|}{${ }^{7}$ Data available from $01 / 07 / 2010$ to $30 / 06 / 2015$} \\
\hline \multicolumn{9}{|c|}{${ }^{8}$ Data available from $30 / 07 / 2010$ to $30 / 06 / 2015$} \\
\hline \multicolumn{9}{|c|}{${ }^{9}$ Data available from $17 / 06 / 2011$ to $30 / 06 / 2015$} \\
\hline \multicolumn{9}{|c|}{${ }^{10}$ Data available from $05 / 10 / 2010$ to $30 / 06 / 2015$} \\
\hline${ }^{11}$ The total gr & wth reflects & s the perce & 然 & +8 & & & & \\
\hline
\end{tabular}


Source: Results are calculated with the help of MS Excel from the data collected from the official website of National Stock Exchange of India.

As seen in Panel B NIFTYBEES has the highest percentage share in terms of Turnover. Its value ranges from $80.81 \%$ in 2011 to $28.96 \%$ in 2015 . It is essential to note that this percentage is falling through the years, with the lowest value in 2015. Considering only the data for 2015, BANKBEES ranks second in terms of percentage turnover, with $56.99 \%$. However, a very small $2.85 \%$ in 2010 , it has an increasing trend through the years. M50 was also having a percentage of $26.59 \%$ in 2010 which gradually declined to $0.42 \%$ in 2015 . Panel C exhibits the yearly turnover growth of ETFs which is found to be maximum in case of BANKBEES. Second is KOTAKNIFTY, third is SHARIABEES. M50 experienced the lowest growth, RELGRNIFTY and JUNIORBEES are in the same line with negative growth if whole period is considered.

Primarily, the study aims to examine the performance of indexed fund investment strategies. In order to achieve this objective, an attempt has been made to examine the risk-return relationship of ETFs, to estimate the tracking error and to measure the effect of expenses and risk on tracking error. Further, the study also estimates the effect of Intraday Volatility, number of trades and lagged return upon the volume of ETFs.

\section{Methodological Inputs}

To achieve the above mentioned objectives, daily closing prices, intraday high and low prices and the volume of the traded shares of 10 ETFs listed on the National Stock Exchange are collected for the period $1^{\text {st }}$ July, 2010 to $30^{\text {th }}$ June, 2015. The non-included ETFs suffer from the restrictions of non-availability of historical prices for at least five years. Every year, starting from $1^{\text {st }}$ July, 2011, average return is calculated for each year of all ETFs. Similarly, returns of their underlying indices have also been taken for the same period.

\subsection{Risk-Return measurement}

Average daily percentage return and risk of ETFs and their corresponding indexes is calculated. Percentage return is calculated using equation (1):

$$
R_{i}=\left(P_{t}-P_{t-1}\right) / P_{t-1} * 100
$$

where, $R_{i}$ refers to the percentage return on day $i$, and $P_{t}$ refers to the closing price of ETF on day $i$. Standard deviation of returns is used to express the risk of ETFs and indexes:

$$
\begin{aligned}
\sigma^{2} & =\sum_{i=1}^{n}\left(A_{i}-\bar{A}\right)^{2} / \mathrm{N}-1 \\
\sigma_{A} & =\sqrt{\sigma_{A}} 2
\end{aligned}
$$

where $\sigma^{2}$ is the variance of an ETF's return around its mean return $\bar{A}$ and $\sigma_{A}$ is the standard deviation of returns and denotes the percentage risk of portfolio. By dividing the mean standard deviation of returns by the average percentage return, 
the risk/return ratio is calculated. This ratio computes the risk tolerated by the investor per unit of return earned. This is an important and useful measure to make comparison between the ETFs. After having a thorough understanding of risk and return characteristics of ETFs, the focus is on the average daily trading turnover, the number of mean executed trades, the volume of traded shares, the expense ratio including management fee and the trading frequency of ETFs.

\subsection{Regression Analysis}

A simple regression is performed to unriddle a variety of interesting issues. Equation (4) presents the single index model:

$$
\mathrm{R}_{\mathrm{pt}}=\alpha_{i}+\beta_{i} \mathrm{R}_{\mathrm{bt}}+\varepsilon_{p t}
$$

where $R_{p t}$ denotes the average return of the ETF, $R_{b t}$ indicates the return of the underlying index and $\varepsilon_{p t}$ is the error term. In this equation, $\alpha$ (alpha) stands for intercept, which is the return an ETF could earn above that return which is related to its underlying index. However, the value of the intercept is not expected to be statistically significant because ETFs adopt passive investment strategies. B (beta) denotes the systematic risk of the ETF and at the same time, it is used to measure the aggressiveness of the management strategy. The extent of replication adopted by the ETF is also explained by the value of its beta. A full replication strategy is indicated by the beta value of unity, in which all the securities in the portfolio assume the same weight as they have in the underlying index. Contrary to it, a beta value which is significantly different from unity indicates a significant departure from the full replication strategy. In this case, the manager of the ETF chooses those stocks which are expected to perform best by implementing his selection strategies.

\subsection{Tracking Error}

The Tracking error is defined as the difference between return of ETF and its underlying index. A manager, who adopts the passive investment strategy, faces the problem of tracking error as he usually fails to replicate the performances of underlying indices. Usually, portfolios formed under this strategy will be efficient if the underlying index's portfolio is efficient. However, their beta is generally greater than unity which is an indicator of higher systematic risk. In this study, tracking error has been calculated with the help of three methods which are most commonly used.

1.In the first method, it is defined as the standard error of simple regression applied in the equation (4) and is denoted as $\mathrm{TE}_{1}$.

2. In the second method, tracking error is computed by taking the average of the difference between the returns of ETFs and their underlying indices. Absolute values of returns' differences are taken as either there is positive or a negative difference, it denotes non-similar performance. It is expressed as $\mathrm{TE}_{2}$ in equation (5). 
Naman SETHI

$$
\mathrm{TE}_{2}=\sum_{t=1}^{n}\left|e_{p}\right| / \mathrm{n}
$$

where $\mathrm{TE}_{2}$ is the tracking error and $\left|e_{p}\right|$ is the absolute return differences.

3. The third method calculates the tracking error as the standard deviation of the return differences between ETFs and their underlying indices. Its estimation is expressed in equation (6).

$$
\mathrm{TE}_{3}=\sqrt{\frac{1}{n-1}} \sum_{t=1}^{n}\left(e_{p t}-\bar{e}_{\mathrm{p}}\right)^{2}
$$

where $e_{p t}$ is the difference of returns in day $t$ and $e_{p}$ is the average return difference over $\mathrm{n}$ days.

\subsection{Performance, Expenses and Risk}

After analyzing the ETFs' risk and return and the different components of tracking error, an attempt is made to study the effect of expenses which include management fee, on the tracking error of ETFs. Previous studies document that the management expenses have a significant impact on ETFs' ability to replicate the performance of their underlying indices. The expense ratios of ETFs have been taken from the official website of NSE.

Cross sectional regression analysis has been applied to measure the impact of expenses on the performance of ETFs. Firstly, a single regression is applied; ETFs average daily return is regressed upon their percentage expense ratio. A negative and statistically significant coefficient of expenses is expected as they reduce the return on ETFs in comparison to indices which do not carry any expenses. Moreover, these expenses are deducted on a daily basis. The tracking error is also regressed on expense ratio to estimate the quantitative relationship between these two. For each estimate of tracking error, distinct regressions are applied. A positive coefficient is expected between these two because greater the management fee the greater the tracking error is expected to be. Risk is considered as a determining factor of the expenses imposed on an ETF investor. It is expected to have a positive impact on the fee charged from investors. The expense ratio is regressed on the standard deviation of returns on ETFs to measure the impact of risk on management fees.

Lastly, the risk is considered to be having a significant impact on the tracking ability

of ETFs i.e. risk is positively related to the tracking error. The three measures of tracking error are regressed on the calculated risk of performance, to know that whether the level of risk affects the calculations of tracking error or not. A positive coefficient is expected between the two.

\subsection{Determinants of Volume}

The study also investigates the factors determining the daily volume of ETFs. There are many factors which affect the daily volume like market volatility and the arbitrage opportunities available to the investors. The Intraday volatility is 
calculated by the ratio of the difference between the daily highest and the daily lowest price on any given day to the closing ETF price on that day. In order to study the inherent trading trend of ETFs, the Intraday volatility of ETFs is a determinant factor of volume.

Traditionally, it is assumed that the number of trades has a positive effect on the volume. Also, both purchases and sales of ETFs have a direct impact on the volume. Similarly, we can also assume that size of the volume is also induced by the return of an ETF on the previous trading day. This assumption is valid for both short and long term investors. Hence, the study intends to find out the relationship between volume and lagged performance of ETFs. For each ETF, a time series regression is run in which volume is a dependent variable and the independent variables are ETF volatility, the number of trades and the lagged return. The regression equation is as follows:

$$
\operatorname{LnVi}=\alpha_{i}+\beta_{i} \frac{\text { DHi and DLi }}{I C i}+\gamma \mathrm{i} \operatorname{Tr}_{\mathrm{i}}+\delta_{\mathrm{i}} \text { LagRet }_{\mathrm{i}}+\varepsilon_{\mathrm{i}}
$$

where $\mathrm{LnVi}$ is the natural logarithm of the daily volume for the ith ETF. $\mathrm{DH}_{\mathrm{i}}$ and $\mathrm{DL}$ are the intraday highest and lowest prices of the ith ETF respectively, and IC denotes the closing price of the same ETF. The $\frac{\text { DHi and DLi }}{I C i}$ ratio calculates the intraday volatility of the ETFs. $\operatorname{Tr}_{i}$ denotes the number of executed trades for the ith

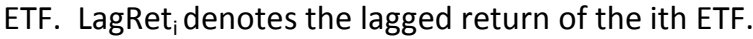

Having assumed that the trading frequency also has an influence on the volume of ETFs, a cross sectional regression is applied for the whole sample of ETFs to examine this phenomenon. ETFs average volatility and the average number of trades as depicted in equation (7) have also been used in the regression. Because the average lagged return is not applicable, hence not used in equation (8). FREQ denotes the trading frequency and is calculated by dividing the actual trading days of ETFs to the total actual trading days of their underlying indices. The regression equation is as follows:

$$
\operatorname{LnVi}=\alpha_{i}+\beta_{i} \frac{\text { DHi and DLi }}{I C i}+\gamma \mathrm{i} \operatorname{Tr}_{\mathrm{i}}+\delta_{\mathrm{i}} \mathrm{FREQ}_{\mathrm{i}}+\varepsilon_{\mathrm{i}}
$$

\section{Results and Discussions}

\subsection{Risk and Return}

Table 3 presents the average risk and return of the sample ETFs, which shows that INFRABEES has the lowest return among all ETFs continuously for three years i.e. from 2011 to 2013 after which it has revived. On the other hand, in 2011 and 2013, RELBANK earned the maximum return, in 2012 and 2015, RELGRNIFTY, and in 2014 SHARIABEES earned the maximum returns respectively. On an average, RELGRNIFTY is the best performer with $0.096 \%$ return and if we compare average returns across the years, we find that year 2014 is the most lucrative with $0.16 \%$ return. 
Naman SETHI

Table 3. Average daily Return of ETFs

\begin{tabular}{lcccccc}
\hline ETF & $\mathbf{2 0 1 1}$ & $\mathbf{2 0 1 2}$ & $\mathbf{2 0 1 3}$ & $\mathbf{2 0 1 4}$ & $\mathbf{2 0 1 5}$ & Average \\
\hline NIFTYBEES & 0.031 & -0.019 & 0.043 & 0.110 & 0.044 & 0.042 \\
JUNIORBEES & 0.001 & -0.029 & 0.061 & 0.149 & 0.080 & 0.052 \\
BANKBEES & 0.076 & -0.025 & 0.057 & 0.149 & 0.062 & 0.064 \\
QNIFTY & 0.036 & -0.020 & 0.066 & 0.138 & 0.052 & 0.055 \\
RELBANK & 0.077 & -0.056 & 0.154 & 0.179 & 0.088 & 0.088 \\
SHARIABEES & 0.011 & 0.000 & 0.056 & 0.261 & 0.097 & 0.085 \\
KOTAKNIFTY & 0.037 & -0.015 & 0.043 & 0.112 & 0.042 & 0.044 \\
M50 & -0.009 & -0.013 & 0.036 & 0.156 & -0.096 & 0.015 \\
RELGRNIFTY & NA & 0.007 & 0.094 & 0.179 & 0.105 & 0.096 \\
INFRABEES & -0.105 & -0.081 & -0.019 & 0.219 & -0.001 & 0.003 \\
Average & 0.017 & -0.025 & 0.059 & 0.165 & 0.047 & \\
Min. & -0.105 & -0.081 & -0.019 & 0.110 & -0.096 & \\
Max. & 0.077 & 0.007 & 0.154 & 0.261 & 0.105 & \\
\hline
\end{tabular}

Source: Results are calculated with the help of MS Excel from the data collected from the official website of National Stock Exchange of India.

Table 4 depicts the risk inherent in each ETF measured by its standard deviation. It shows that average standard deviation is maximum in the year 2014 i.e. 1.94\%, supporting the belief that higher return commensurate higher risk. Comparing across years, it is found that year 2011 is faced with least risk which is equal to $1.27 \%$. Among the ETFs, NIFTYBEES is the least risky and SHARIABEES is the most risky ETF on an average.

Table 4. Standard Deviation of ETFs

\begin{tabular}{lcccccc}
\hline ETF & $\mathbf{2 0 1 1}$ & $\mathbf{2 0 1 2}$ & $\mathbf{2 0 1 3}$ & $\mathbf{2 0 1 4}$ & $\mathbf{2 0 1 5}$ & Average \\
\hline NIFTYBEES & 1.035 & 1.203 & 0.855 & 1.019 & 0.831 & 0.989 \\
JUNIORBEES & 1.192 & 1.404 & 1.048 & 1.195 & 1.158 & 1.200 \\
BANKBEES & 1.391 & 1.575 & 1.234 & 1.793 & 1.316 & 1.462 \\
QNIFTY & 1.037 & 1.320 & 0.889 & 1.202 & 0.930 & 1.076 \\
RELBANK & 1.806 & 2.044 & 2.485 & 2.723 & 1.686 & 2.149 \\
SHARIABEES & 1.304 & 2.483 & 2.765 & 4.002 & 3.008 & 2.712 \\
KOTAKNIFTY & 1.040 & 1.374 & 0.831 & 1.063 & 0.826 & 1.027 \\
M50 & 1.275 & 1.651 & 1.172 & 1.328 & 2.326 & 1.550 \\
RELGRNIFTY & NA & 2.772 & 2.251 & 2.548 & 2.615 & 2.547 \\
INFRABEES & 1.352 & 1.996 & 2.050 & 2.579 & 1.542 & 1.904 \\
Average & 1.270 & 1.782 & 1.558 & 1.945 & 1.624 & \\
Min. & 1.035 & 1.203 & 0.831 & 1.019 & 0.826 & \\
Max. & 1.806 & 2.772 & 2.765 & 4.002 & 3.008 & \\
\hline Soure: Result & $c .45 t e d$ & &
\end{tabular}

Source: Results are calculated with the help of MS Excel from the data collected from the official website of National Stock Exchange of India.

Table 5 presents the comparison of ETFs with their underlying indices and their average risk/return ratios. As the number of observations for each ETF is different due to non-availability of data, hence average returns of their underlying indices are also different. It is curious to note that the CNX Infra Index is having the maximum return of $10.83 \%$, which is substantially higher than the other indices. 
Bank Nifty ranks second with $1.62 \%$ and Shariah Index ranks last with $0.03 \%$. As far as risk is concerned, again CNX Infra presents a risk highest among all indices, i.e. $96.6 \%$, Bank Nifty again ranks second with $30.4 \%$ and Shariah Index ranks last with $0.97 \%$. A large range is observed between the minimum and maximum values of average risk/return ratio. Specifically, INFRABEES is having the largest value of this ratio which is equal to 709.5, and it emerges as an outlier. This ratio is 104.8 for M50 while it ranges from 19.7 to 31.9 for all other ETFs.

Table 5. Daily Percentage Return and Risk of ETFs and their Underlying Indices

\begin{tabular}{|c|c|c|c|c|c|c|c|c|}
\hline \multirow[b]{2}{*}{ ETF Name } & \multirow[b]{2}{*}{ Underlying Index } & \multicolumn{2}{|c|}{ Return } & \multicolumn{2}{|c|}{ Risk } & \multicolumn{2}{|c|}{ Risk/Return Ratio } & \multirow{2}{*}{ Obs. } \\
\hline & & ETF & Index & ETF & Index & ETF & Index & \\
\hline NIFTYBEES & Nifty & 0.042 & 0.042 & 0.989 & 1.051 & 23.588 & 24.964 & 1244 \\
\hline JUNIORBEES & Junior Nifty & 0.052 & 0.051 & 1.200 & 1.116 & 23.007 & 21.704 & 1244 \\
\hline BANKBEES & Bank Nifty & 0.064 & 1.627 & 1.462 & 30.393 & 22.841 & 18.676 & 1244 \\
\hline QNIFTY & Nifty & 0.055 & 0.042 & 1.076 & 1.051 & 19.735 & 24.964 & 1049 \\
\hline RELBANK & Bank Nifty & 0.088 & 1.627 & 2.149 & 30.393 & 24.284 & 18.676 & 1214 \\
\hline SHARIABEES & Shariah Index & 0.085 & 0.038 & 2.712 & 0.973 & 31.904 & 25.482 & 1062 \\
\hline KOTAKNIFTY & Nifty & 0.044 & 0.042 & 1.027 & 1.051 & 23.543 & 24.964 & 1240 \\
\hline M50 & Nifty & 0.015 & 0.041 & 1.550 & 1.057 & 104.888 & 25.591 & 1221 \\
\hline RELGRNIFTY & Nifty & 0.096 & 0.049 & 2.547 & 1.051 & 26.443 & 21.294 & 692 \\
\hline INFRABEES & CNX Infra Index & 0.003 & 10.837 & 1.904 & 96.594 & 709.590 & 8.913 & 1166 \\
\hline
\end{tabular}

Source: Results are calculated with the help of MS Excel from the data collected from the official website of National Stock Exchange of India.

Table 6. Volume and Expense Ratios of ETFs

\begin{tabular}{lccccc}
\hline \multicolumn{1}{c}{ ETF } & $\begin{array}{c}\text { Daily Turnover } \\
\text { (in lakhs) }\end{array}$ & Trades & Volume & Expense ratio & $\begin{array}{c}\text { Trading } \\
\text { Frequency }\end{array}$ \\
\hline NIFTYBEES & 430.64 & 1665.19 & 70663.83 & $0.80 \%$ & 1.00 \\
JUNIORBEES & 46.83 & 239.43 & 35090.47 & $1 \%$ & 1.00 \\
BANKBEES & 185.99 & 176.64 & 7585.73 & $0.50 \%$ & 1.00 \\
QNIFTY & 0.57 & 6.17 & 92.03 & $0.75 \%$ & 0.85 \\
RELBANK & 3.08 & 25.78 & 195.93 & $0.80 \%$ & 0.97 \\
SHARIABEES & 0.61 & 7.94 & 334.63 & $1 \%$ & 0.86 \\
KOTAKNIFTY & 61.76 & 71.96 & 7895.13 & $0.39 \%$ & 1.00 \\
M50 & 47.07 & 192.58 & 39916.22 & $1.31 \%$ & 0.99 \\
RELGRNIFTY & 1.51 & 6.66 & 310.81 & $0.75 \%$ & 0.56 \\
INFRABEES & 3.42 & 35.11 & 1059.38 & $1.11 \%$ & 0.94 \\
Average & 78.15 & 242.75 & 16314.42 & $0.84 \%$ & 0.92 \\
Min & 0.57 & 6.17 & 92.03 & $0.39 \%$ & 0.56 \\
Max & 430.64 & 1665.19 & 70663.83 & $1.31 \%$ & 1.00 \\
\hline SOUre: RESt & &
\end{tabular}

Source: Results are calculated with the help of MS Excel from the data collected from the official website of National Stock Exchange of India.

\subsection{Regression Analysis}

Table 7 presents the results of Single index regression model. No ETF is having statistically significant alpha which is in line with our expectations because ETFs are 
Naman SETHI

generally passive replicators of the performance of their underlying indices and they do not produce returns superior than their indices.

Table 7. Results of Single Index Regression Model

\begin{tabular}{lllllll}
\hline ETF & A & t-test & B & t-test & $\mathbf{R}^{2}$ & Obs. \\
\hline NIFTYBEES & 0.0361 & 1.288 & $0.1342^{*}$ & 5.029 & 0.020 & 1244 \\
JUNIORBEES & 0.0087 & 0.403 & $0.8368^{*}$ & 43.199 & 0.600 & 1244 \\
BANKBEES & 0.0577 & 1.358 & $0.0028^{* * *}$ & 1.801 & 0.003 & 1216 \\
QNIFTY & 0.0321 & 1.315 & $0.6906^{*}$ & 30.682 & 0.474 & 1048 \\
RELBANK & 0.0734 & 1.158 & 0.0021 & 0.925 & 0.001 & 1192 \\
SHARIABEES & 0.0673 & 0.786 & $0.4956^{*}$ & 5.628 & 0.029 & 1061 \\
KOTAKNIFTY & 0.0388 & 1.314 & $0.1104^{*}$ & 3.931 & 0.012 & 1240 \\
M50 & 0.0137 & 0.297 & 0.0429 & 0.981 & 0.001 & 1220 \\
RELGRNIFTY & 0.0545 & 0.571 & $0.4010^{*}$ & 4.546 & 0.029 & 691 \\
INFRABEES & 0.0140 & 0.240 & -0.0006 & -1.019 & 0.001 & 1165
\end{tabular}

Note: $*$ Statistically significant at $1 \%$ level. ${ }^{* * *}$ Statistically significant at $10 \%$ level

Source: Results are calculated with the help of MS Excel from the data collected from the official website of National Stock Exchange of India.

On the contrary, 7 out of 10 estimations of beta are statistically significant, 6 at 1\% and 1 at $10 \%$. Further, t-statistics indicate that ETF betas are different from unity which means that the sample ETFs do not apply a full replication strategy. Probably, the underperformance of ETFs relative to their underlying indices which was found earlier is explained partially by this insufficient replication of indices. If individual betas are considered, we see that the most substantial deviations from unity concern mainly the ETFs which track the sectoral indices like BANKBEES and RELBANK which track Bank Nifty and INFRABEES which track CNX Infra Index. While examining the ETF replication strategy, we use the value of $R^{2}$, which seems to be very less in almost all the ETFs. Also, the difference of average R-square from unity is statistically significant at the $10 \%$ level, which indicates that these ETFs are not fully invested in the assets of their underlying index portfolios.

\subsection{Tracking Error}

Table 8 depicts the results of estimation of tracking error by three measures and the average tracking error of ETFs.

The tracking error is as low as 0.58 and as high as 97.01 . The mean tracking error of all the three measures is 7.47 , which is considered to be significant, reflecting the substantial deviation among ETFs and their underlying indices' performances. Average tracking error is minimum in JUNIORBEES i.e. 0.71 and maximum in INFRABEES i.e. 42.8. Insufficient replication of the underlying indices by the ETFs is found to be the significant cause for the existence of such large tracking errors. It may also be due to infrequent trading in some ETFs. Parallel to these results, the trading frequency (Table 6) of JUNIORBEES is 1.00 and that of INFRABEES is 0.94, suggesting another factor behind lower tracking error. Further, the expense ratio of JUNIORBEES is $1 \%$ and that of INFRABEES is $1.11 \%$. 
Table 8. Estimation of Tracking Error

\begin{tabular}{lcccc}
\hline \multicolumn{1}{c}{ ETF } & $\mathrm{TE}_{\mathbf{1}}$ & $\mathrm{TE}_{\mathbf{2}}$ & $\mathrm{TE}_{\mathbf{3}}$ & Average $\mathrm{TE}_{(1+2+3)}$ \\
\hline NIFTYBEES & 0.988 & 1.011 & 1.343 & 1.114 \\
JUNIORBEES & 0.762 & 0.587 & 0.783 & 0.711 \\
BANKBEES & 1.481 & 2.361 & 27.158 & 10.333 \\
QNIFTY & 0.789 & 0.648 & 0.857 & 0.765 \\
RELBANK & 2.188 & 3.524 & 28.528 & 11.413 \\
SHARIABEES & 2.785 & 1.907 & 2.826 & 2.506 \\
KOTAKNIFTY & 1.040 & 1.019 & 1.399 & 1.153 \\
M50 & 1.607 & 1.320 & 1.896 & 1.608 \\
RELGRNIFTY & 2.503 & 1.832 & 2.584 & 2.306 \\
INFRABEES & 1.976 & 29.406 & 97.011 & 42.798 \\
Average & 1.612 & 4.361 & 16.439 & 7.47 \\
Min. & 0.762 & 0.587 & 0.783 & 0.71 \\
Max. & 2.785 & 29.406 & 97.011 & 42.80 \\
\hline
\end{tabular}

Source: Results are calculated with the help of MS Excel from the data collected from the official website of National Stock Exchange of India.

\subsection{Performance, Expenses and Risk}

Table 9 depicts the results of Cross Sectional Regressions between returns, expenses, tracking error and risk of ETFs. At the beginning of this table, returns are regressed upon expenses as there is a crucial influence of expenses on ETF performance.

\section{Table 9. Results of Cross Section Regressions}

\begin{tabular}{ccclccc}
\hline Model & $\boldsymbol{\alpha}$ & t-test & $\boldsymbol{\beta}$ & t-test & $\mathbf{R}^{2}$ & No. of Funds \\
\hline $\mathrm{R}_{\mathrm{i}}=\alpha_{i}+\beta_{i} \mathrm{ER}_{\mathrm{i}}+\varepsilon_{i}$ & $0.09 *$ & 2.93 & -4.56 & -1.27 & 0.17 & 10 \\
$\mathrm{TE}_{1 \mathrm{i}}=\alpha_{i}+\beta_{i} \mathrm{ER}_{\mathrm{i}}+\varepsilon_{i}$ & 1.06 & 1.33 & 65.25 & 0.72 & 0.06 & 10 \\
$\mathrm{TE}_{2 \mathrm{i}}=\alpha_{i}+\beta_{i} \mathrm{ER}_{\mathrm{i}}+\varepsilon_{i}$ & -4.57 & -0.48 & 1062.22 & 0.99 & 0.11 & 10 \\
$\mathrm{TE}_{3 \mathrm{i}}=\alpha_{i}+\beta_{i} \mathrm{ER}_{\mathrm{i}}+\varepsilon_{i}$ & -3.44 & -0.10 & 2363.37 & 0.62 & 0.05 & 10 \\
\hline Average & -2.32 & 0.25 & 1163.61 & 0.78 & 0.07 & 10 \\
\hline $\mathrm{ER}_{\mathrm{i}}=\alpha_{i}+\beta_{i} \mathrm{RISK}_{\mathrm{i}}+\varepsilon_{i}$ & $0.01^{* *}$ & 2.47 & 0.00 & 0.82 & 0.08 & 10 \\
$\mathrm{TE}_{1 \mathrm{i}}=\alpha_{i}+\beta_{i} \mathrm{RISK}_{\mathrm{i}}+\varepsilon_{i}$ & -0.24 & -1.60 & $1.12^{*}$ & 12.95 & 0.95 & 10 \\
$\mathrm{TE}_{2 \mathrm{i}}=\alpha_{i}+\beta_{i} \mathrm{RISK}_{\mathrm{i}}+\varepsilon_{i}$ & -0.14 & -0.02 & 2.71 & 0.56 & 0.04 & 10 \\
$\mathrm{TE}_{3 \mathrm{i}}=\alpha_{i}+\beta_{i} \mathrm{RISK}_{\mathrm{i}}+\varepsilon_{i}$ & 0.78 & 0.03 & 9.42 & 0.57 & 0.04 & 10 \\
\hline Average & & -0.53 & $4.42^{*}$ & 4.70 & 0.34 & 10 \\
\hline
\end{tabular}

Where:

$R$ is the average daily return of ETFs

$E R$ is the Expense ratio of ETFs

$\mathrm{TE}_{1}$ refers to the standard errors of regression (4).

$\mathrm{TE}_{2}$ is the average of the absolute return difference between ETF and index.

$\mathrm{TE}_{3}$ is the standard deviation of the return difference between ETF and index.

Risk is the standard deviation of daily returns.

*Statistically significant at the $1 \%$ level. ${ }^{* *}$ Statistically significant at the $5 \%$ level.

Source: Results are calculated with the help of MS Excel from the data collected from the official website of National Stock Exchange of India. 
The results show a negative effect of expenses on performance with a regression coefficient of -4.56 and a significant intercept of 0.09 . Past studies indicate a significant influence of expenses on the tracking error of ETFs. To study the magnitude of this impact, tracking error is regressed upon the expense ratios of ETFs. A separate regression is run for each one of the three methods of measurement of tracking error. The results indicate a positive relationship between the two, implying that the expenses count for a large chunk of ETFs' tracking error.

The risk of the ETFs is also considered as a determining factor of expense ratios. This relationship is being investigated by regressing the expense ratio to the standard deviation of returns. The results indicate a significant intercept of 0.01 which is equal to the expense ratios of most ETFs. Regression coefficient is equal to zero, indicating no impact of risk on expense ratios of Indian ETFs. The last part of the table presents the results of the relationship between tracking error and risk of ETFs. For this purpose, all the three measurements of tracking error are regressed upon the standard deviation of returns. The coefficients are found to be significant and positive at $1 \%$ level of significance, which indicates that the presence of risk affects the replication ability of ETFs.

\subsection{Determinants of Volume}

Table 10 presents the estimations of volume determinants shown in models (7) and (8). Model (7) explores the impact of Intraday volatility of ETFs, number of trades and lagged return upon the volume of ETFs.

A time series regression is applied for each ETF in the sample. Model (8) explains the cross sectional regression of ETFs volume upon the average Intraday volatility, the average number of executed trades and the trading frequency of the sample ETFs. The results reveal that intercept value is positive and statistically significant at $1 \%$ for all ETFs, which implies that a significant proportion of shares is traded independent of Intraday volatility, the number of trades and the lagged return. A great interest of investors is visible while investing their funds in ETFs in the form of this independent trading. The various benefits of ETFs are considered to be the main factor behind this interest of investors, which include liquidity, tax benefits, convenience in trading and flexibility in executed intraday orders.

The regression coefficient for intraday volatility is also positive and statistically significant at $1 \%$ for all ETFs, implying a positive influence on ETF volume. The regression coefficients for the number of trades and the lagged return are found to be near to zero and also significant at $1 \%$ which implies no significant impact on ETFs volume. The return of the previous day is not found to motivate the investors to invest in an ETF. This finding goes against the common belief that previous returns or losses persuade the investors to invest or disinvest their funds in the securities, particularly in the short run. Finally, $R^{2}$ of INFRABEES is highest among all with 0.27 and that of M50 is the lowest i.e. 0.06 . 
Table 10. The Determinants of Volume- Time Series Analysis

\begin{tabular}{|c|c|c|c|c|c|c|c|c|c|c|}
\hline ETF & $\alpha$ & t-test & $\beta$ & t-test & $v$ & t-test & $\delta$ & t-test & $\mathbf{R}^{2}$ & Obs. \\
\hline NIFTYBEES & $4.42^{*}$ & 229.06 & $5.46^{*}$ & 6.69 & $0.00 *$ & 12.95 & 0.00 & -0.02 & 0.20 & 1012 \\
\hline JUNIORBEES & $3.91^{*}$ & 120.82 & $7.74^{*}$ & 8.70 & $0.00 *$ & 4.62 & 0.01 & 1.09 & 0.10 & 1012 \\
\hline BANKBEES & $2.91 *$ & 83.05 & $6.67 *$ & 7.16 & $0.00 *$ & 8.55 & 0.01 & 0.69 & 0.12 & 1012 \\
\hline QNIFTY & $1.35^{*}$ & 44.65 & $6.24^{*}$ & 7.75 & $0.01 *$ & 3.97 & -0.01 & -0.73 & 0.09 & 836 \\
\hline RELBANK & $1.45^{*}$ & 55.92 & $9.00 *$ & 17.17 & $0.00 *$ & 2.44 & 0.01 & 0.85 & 0.24 & 981 \\
\hline SHARIABEES & $1.62^{*}$ & 47.88 & $7.62^{*}$ & 12.77 & 0.00 & 0.67 & 0.01 & 0.85 & 0.16 & 856 \\
\hline KOTAKNIFTY & $2.84^{*}$ & 81.78 & $3.02 *$ & 2.70 & $0.00 *$ & 15.16 & 0.03 & 1.20 & 0.20 & 1008 \\
\hline M50 & $3.79 *$ & 133.19 & $3.80 *$ & 5.11 & $0.00 *$ & 4.93 & $0.03^{*}$ & 3.36 & 0.06 & 1010 \\
\hline RELGRNIFTY & $1.42^{*}$ & 39.48 & $5.42 *$ & 6.80 & $0.03^{*}$ & 9.36 & 0.00 & -0.06 & 0.17 & 689 \\
\hline INFRABEES & $2.07^{*}$ & 67.06 & $9.58^{*}$ & 15.18 & $0.00 *$ & 10.68 & 0.00 & 0.30 & 0.27 & 1001 \\
\hline
\end{tabular}

*Statistically significant at $1 \%$. Source: Results are calculated with the help of MS Excel from the data collected from the official website of National Stock Exchange of India.

Table 11 presents the results of regression of model (8) which is applied on the average of all ETFs. The results are contrary to the results of individual ETFs in the manner that intercept value is negative but not statistically significant. Regression coefficient of volatility is also negative while that of number of trades and trading frequency is positive and also significant at $10 \%$. Trading frequency is found to have a strong influence on volume of ETFs.

Table 11. The Determinants of Volume- Cross-sectional Analysis

\begin{tabular}{lll}
\hline Variable & Coefficient & t-test \\
\hline Constant & -0.7442 & -0.381 \\
ETFs Volatility & -12.0786 & -0.338 \\
Number of Trades & $0.0011^{* * *}$ & 1.787 \\
Trading Frequency & $3.9685^{* * *}$ & 1.875 \\
$\mathrm{R}^{2}$ & 0.661 & \\
Obs. & 10 & \\
\hline
\end{tabular}

*** Statistically significant at $10 \%$.

Source: Results are calculated with the help of MS Excel from the data collected from the official website of National Stock Exchange of India.

\section{Conclusions}

The study focuses on Indian ETFs listed on the National Stock Exchange while most of the literature covers the US and Canadian ETFs. The results show that average percentage turnover is increasing across the years, implying a significant growth and increased interest of investors in ETFs. The study investigates the percentage risk and return of ETFs and their underlying indices and finds that ETFs underperform their benchmarks and load their investors with extra risk than their underlying indices. These results indicate that the Indian ETFs are not able to fully replicate their benchmarks. Their less than unity betas are preventing them from full replication of underlying indices, while protecting them during bear markets. The study estimates tracking error of ETFs which is equal to a substantial $7.47 \%$, on an average which reflects the incomplete replication of the underlying indices by 
the ETFs. Further, it is found that tracking error is having a positive relationship with expenses and risk of ETFs. Also, expenses are found to be having a negative impact on the performance of ETFs. The study finds a positive impact of Intraday volatility on the volume of ETFs. Interestingly, the average number of trades and the lagged return of previous day do not affect the volume of shares. This finding is in contrast to the common belief that previous performance induces the investors at least in the short run.

Overall, the empirical findings are in line with the previous studies in other ETF markets. Like, Frino and Galagher (2002), it is found that ETFs carry a significant tracking error due to lack of full replication of their underlying indices. Similarly, Frino et.al. (2004) and Milonas and Rompotis (2006) came out with the same results that ETFs underperform their benchmarks and burden their investors with more risk than the standard deviation of their underlying indices. Also, the ETFs are having betas lower than unity. Moreover, the study comes out with a new set of interactions between the performance, expenses and risk. Expenses are positively affected by the risk, but they themselves negatively impact the performance of ETFs. Risk is found to be a significant determinant of expenses with $R^{2}$ of 0.08 . Finally, it is an attempt to study and analyze the varied characteristics of Indian ETFs and the interrelationship among them.

\section{References}

Frino, A., \& Gallagher, D. R. (2002). Is Index Performance Achievable? An Analysis of Australian Equity Index Funds. Abacus, 38 (2), 200-214. retrieved on April 302015 from https://doi.org/10.1111/1467-6281.00105.

Dhanda, S. K., Batra, G. S., \& Anjum, B. (2012). Performance evaluation of selected open ended mutual funds in India. International Journal of Marketing, Financial Services \& Management Research, 1(1).

Dellva, W.L. (2001). Exchange-traded funds not for everyone. Journal of Financial Planning, 14 (4), $110-124$.

Frino, A., Gallagher, D. R. \& Oetomo, T. N. (2005). The index tracking strategies of passive and enhanced index equity funds. Australian Journal of Management, 30(1), 23-55. https://doi.org/10.1177/031289620503000103

Gastineau, G. L. (2004). The benchmark index ETF performance problem: A simple solution. Journal of Portfolio Management, 30(2), 96 - 103. https://doi.org/10.3905/jpm.2004.319935

Gruber, M. J. (1996). Another puzzle: The growth in actively managed mutual funds. Journal of Finance, 51, 783-810. https://doi.org/10.1111/j.1540-6261.1996.tb02707.x

Len, S., Mercado, S. \& Rejendra, A. (2014). Synthetic equity \& index strategy: ETF annual review \& outlook. Deutsche Bank Markets Research. Retrieved on July 252015 from https://www.altii.de/media/modelfield files/fondsportal/pressrelease/pdf/Deutsche Bank Research ETF Market Review 2014 Outlook 2015.pdf

Lin, C. C., Chan, S. J., \& Hsu, H. (2006). Pricing efficiency of exchange traded funds in Taiwan. Journal of Asset Management, 7(1), 60-68. 
Milonas, N. T. \& Rompotis, G. G. (2006). Investigating European ETFs: The case of the Swiss exchange traded funds. Annual Conference of HFAA in Thessaloniki, Greece. Retrieved on April 30 2015 from http://citeseerx.ist.psu.edu/viewdoc/download?doi=10.1.1.524.9571\&rep=rep1\&type=pdf Pastor, B., R. (2012). Are index fund investors rational? The effect of fund characteristics on performance and cash flows. Retrieved on May 2, 2015 from http://arno.uvt.nl/show.cgi?fid=128260.

Prajapati, K. P., \& Patel, K. (2012). Comparative study on performance evaluation of mutual fund schemes of Indian companies. Journal of Arts, Science \& Commerce, 3(3), 47-59.

Wang, L., Hussain, I., \& Ahmed, A. (2010). Gold exchange traded funds: Current developments and future prospects in China. Asian Social Science, 6(7), 119.

Welch, S. (2007). On performance \& tracking error in exchange-traded funds and index mutual funds. Saint John's University, Accounting and Finance Faculty Publications. Paper 7. Retrieved on October 17, 2015 from http://digitalcommons. csbsju.edu/cgi/viewcontent.cgi?article $=1006 \&$ context $=$ acct pubs 